\title{
KETERLIBATAN KELUARGA DALAM TATA KELOLA DAN ORGANISASI PERUSAHAN PADA KONTEKS ENTREPRENEURIAL ORIENTATION
}

\author{
Krismi Budi Sienatra ${ }^{1 *}$ Syellen Laudo ${ }^{2}$ \\ ${ }^{1,2}$ Fakultas Manajemen dan Bisnis, Universitas Ciputra, Indonesia \\ krismi.budi@ciputra.ac.id ${ }^{1}$, syellenlau@gmail.com ${ }^{2}$ \\ *Corresponding author
}

\begin{abstract}
Abstrak : Keterlibatan Keluarga Dalam Tata Kelola Dan Organisasi Perusahan Pada Konteks Entrepreneurial Orientation Perusahaan keluarga sebagai kontributor terbesar dalam pertumbuhan ekonomi, seringkali memiliki performa yang inkonsisten. Penelitian ini bertujuan mengetahui bagaimana dimensi entrepreneurial orientation dapat memberi pengaruh terhadap family firm performance. Penelitian ini menggunakan tiga dimensi entrepreneurial orientation terdiri dari innovativeness, proactiveness dan risk taking. Keterlibatan keluarga dalam pengelolaan perusahaan keluarga digunakan sebagai moderasi apakah memiliki dampak pada family firm performance. Sampel dari penelitian ialah komunitas perusahaan keluarga yang dibentuk dari universitas di Surabaya. Penelitian menggunakan alat analisis PLS. Hasil penelitian memperlihatkan bahwa proactiveness berpengaruh signifikan terhadap family firm performance sedangkan innovativeness dan risk taking tidak berpengaruh. Hasil moderasi menunjukkan keterlibatan keluarga tidak memoderasi dimensi entrepreneurial orientation terhadap family firm performance. Temuan ini memberikan gambaran bagi perusahaan keluarga yang masih skala menengah dan kecil serta belum terbuka dengan melibatkan anggota keluarga dalam tata kelola organisasi belum memiliki dampak pada kinerja perusahaan. Keterlibatan anggota keluarga hanya bersifat administratif bagi pemillik perusahaan.

Kata kunci: entrepreneurship orientation, perusahaan keluarga, performa perusahaan keluarga
\end{abstract}

\begin{abstract}
Family Involvement In Governance And Company Organizations In The Context Of Entrepreneurial Orientation. Family companies, as the biggest contributors to economic growth, often have an inconsistent performance. This study aims to determine how the dimensions of entrepreneurial orientation can have an influence on family firm performance. This study uses three dimensions of entrepreneurial orientation consisting of innovativeness, proactiveness and risk taking. Family involvement in the management of family companies is used as moderation whether it has an impact on family firm performance. The sample of this research is a family company community formed from a university in Surabaya. The research used PLS analysis tool. The results showed that proactiveness had a significant effect on family firm performance, while innovativeness and risk taking had no effect. The result of moderation shows that family involvement does not moderate the dimensions of entrepreneurial orientation towards family firm performance. These findings provide an overview for family companies that are still medium and small in scale and have not been open to involving family members in organizational governance yet have an impact on company performance. The involvement of family members is only administrative in nature for company owners Keywords: entrepreneurship orientation, family firm, family firm performance
\end{abstract}

\begin{tabular}{ccccc}
\hline \hline \multirow{4}{*}{ History \& License of Article Publication: } & \\
Received: & $23 / 01 / 2021 \quad$ Revision: & $31 / 01 / 2021$ & Published: & $28 / 02 / 2021$ \\
\hline & & & \\
& DOI: https://doi.org/10.21831/efisiensi.v17i1.38166 & \\
\hline
\end{tabular}




\section{PENDAHULUAN}

Perusahaan keluarga mendominasi jumlah bisnis yang terdaftar di berbagai negara. Pada negara Indonesia, 95\% bisnis yang terdaftar merupakan perusahaan keluarga (International Finance Corporation (IFC), 2016). Peranan perusahaan keluarga sangatlah berdampak pada pertumbuhan ekonomi dalam suatu negara. Secara keseluruhan, perusahaan keuarga menyumbang hasil PDB global tiap tahun sebanyak 70 hingga 90\%, selain itu perusahaan keluarga juga menciptakan lapangan kerja sekitar 50 hingga $80 \%$ di mayoritas negara di seluruh dunia (Family Firm Institute Inc., 2017). Perusahaan keluarga ialah perusahaan yang kepemilikan sahamnya didominasi oleh anggota keluarga sebesar 51\%, manajemen perusahaan diurus dan dikontrol oleh anggota keluarga, serta memiliki generasi penerus sebagai suksesor perusahaan (Wijaya \& Wijaya, 2017).

Kondisi secara umum performa perusahaan keluarga di Indonesia pada tahun 2016 memiliki hasil yang tidak terlalu bagus secara finansial. Penurunan penjualan perusahaan keluarga di Indonesia mencapai angka 44\%, sedangkan pertumbuhan penjualan sebesar $42 \%$. Dua tahun kemudian, yaitu tahun 2018, performa pertumbuhan finansial di Indonesia menjadi lebih baik dengan hasil pertumbuhan penjualan sebesar $65 \%$ dan penurunan penjualan hanya sebesar $7 \%$. Terdapat pula berbagai tantangan yang dirasakan oleh perusahaan keluarga di Indonesia. Tantangan terbesar ialah mengakses keterampilan dan kemampuan yang tepat dalam perusahaan, lalu diikuti dengan adanya kebutuhan perusahaan untuk berinovasi agar dapat terus maju. Selain tantangan yang berasal dari internal, terdapat pula tantangan yang berasal dari eksternal yaitu, lingkungan ekonomi, kompetisi domestik, kompetisi internasional dan regulasi (Price Waterhouse Coopers, 2018).

Agar dapat bertahan dan berkelanjutan dalam pasar, perusahaan perlu menangani krisis dengan melibatkan kegiatan inovasi dalam organisasi yang bersifat positif. Performa perusahaan dapat menjadi lebih baik karena adanya inovasi (Kuswantoro, 2015). Seringkali, kondisi krisis akan mendorong organisasi untuk melakukan kegiatan inovatif, bertindak secara proaktif dan mengambil keputusan meskipun terdapat risiko yang mengikutinya (Ratten, 2020). Sikap tersebut merupakan dimensi entrepreneurial orientation yang terdiri dari innovativeness, proactiveness dan risk taking. Perusahaan yang menerapkan entrepreneurial orientation mampu merealisasikan target pertumbuhan dan perkembangan, serta mampu memiliki daya saing yang lebih tingi dibandingkan perusahaan yang tidak menerapkan entrepreneurial orientation (Winata \& Wijaya, 2019). 
Innovativeness merupakan komponen kunci entrepreneurship yang mampu mendorong perusahaan menghasilkan ide-ide kreatif yang membentuk value baru perusahaan. Dengan adanya inovasi, perusahaan akan mempunyai keunggulan kompetitif baru dan menemukan peluang baru yang berkaitan dengan permintaan masa depan. Saat menentukan keputusan, dibutuhkan kemampuan strategis yang bersifat jeli terhadap perubahan dan peluang di pasar, tindakan ini ialah sikap proaktif. Melalui proactiveness, perusahaan akan mampu untuk mengantisipasi tantangan yang akan datang, bahkan menemukan celah peluang dalam tantangan tersebut. Dalam setiap kegiatan bisnis, pengambilan keputusan sebagai bentuk dari komitmen organisasi tidak dapat lepas dari adanya risiko (Hasan, 2019). Hal ini disebabkan karena peluang selalu diikuti dengan adanya persaingan ketat dari kompetitor. Sehingga, kemampuan risk taking seorang entrepreneur sangat diperlukan untuk meminimalisir risiko dan agar peluang terbaik dapat didapat walaupun situasinya tidak pasti (Cho \& Lee, 2018).

Berbagai penelitian telah dilaksanakan oleh banyak peneliti di bidang manajemen bisnis, ekonomi, dan entrepreneurship untuk mengidentifikasi hal-hal apa saja yang mampu mempengaruhi performa suatu perusahaan. Mayoritas penelitian dilaksanakan di berbagai macam negara (Aloulou, 2018) (Basco et al., 2019) (Chong et al., 2019) (Hernández-Linares et al., 2019) (Hernandez-Perlines, 2018) (Winata \& Wijaya, 2019) yang meneliti tentang keterhubungan antara entrepreneurial orientation dengan family firm performance. Hasil dari mayoritas penelitian terdahulu yang telah dilakukan, dapat ditarik kesimpulan utama bahwa dimensi proactiveness pada entrepreneurial orientation selalu berpengaruh signifikan terhadap performa perusahaan keluarga. Pada beberapa penelitian terdahulu masih terdapat hasil inkonsisten dimana dimensi innovativeness dan risk taking tidak berpengaruh terhadap performa perusahaan keluarga, namun terdapat pula penelitian yang menunjukkan hasil hubungan yang positif dan signifikan. Meskipun telah ada berbagai penelitian yang meneliti mengenai entrepreneurial orientation terhadap family firm performance, studi empiris yang dilaksanakan pada negara di Asia Tenggara masih minim khususnya di Indonesia. Di Indonesia masih jarang yang meneliti pada perusahaan keluarga yang masih tertutup dimana kebanyakan meneliti pada perusahaan keluarga yang go public (Winata \& Wijaya, 2019) dengan hasil dimensi entrepreneurial orientation semua memiliki pengaruh terhadap kinerja perusahaan. Penelitian ini memfokuskan pada perusahaan keluarga yang masih tertutup dengan karakteristik yang berbeda dengan perusahaan terbuka 
seperti struktur organisasi yang lebih sederhana dan kemampuan ekpansi yang lebih kecil dibandingkan perusahaan terbuka. Penelitian ini bertujuan ini ialah untuk menguji dimensi entrepreneurial orientation apa saja yang mampu mempengaruhi performa perusahaan keluarga yang masih tertutup dengan skala kecil dan menengah dengan menyertakan keterlibatan anggota keluarga (family involvement) sebagai pemoderasi karena dalam perusahaan keluarga keterlibatan anggota keluarga lain dalam tata kelola perusahaan dalam organisasi selalu ada.

\section{Perumusan Hipotesis}

Inovasi yang ada di family business mampu membentuk sustainability dan long-term performance (Olaore \& Oyeleke, 2019). Dalam kegiatan berbisnis, inovasi adalah upaya pengidentifikasian dan berinvestasi pada lingkungan sosial untuk menemukan peluang inovatif yang layak diinvestasikan (Mullens, 2018). (Hatak et al. 2016) menemukan hasil dimensi innovativeness menunjuk pada kemampuan sebuah perusahaan dalam mengembangkan dan mengenalkan produk baru yang menyebabkan terjadinya peningkatan kinerja perusahaan.

Proaktif pada perusahaan bertujuan pada perspektif masa mendatang yang disertai dengan tindakan pengenalan produk / layanan baru untuk membentuk potensi permintaan dan menerima keunggulan kompetitif yang berbeda dibandingkan dengan para pesaing (Linton \& Kask, 2017). Tindakan proaktif dalam suatu perusahaan memungkinkannya untuk mengetahui celah dan memanfaatkan kesempatan tersebut (Chong et al., 2019). Fungsi utama tingginya penerapan nilai entrepreneurial orientation adalah bagaimana suatu perusahaan mampu melaksanakan pengukuran dan pengambilan risiko secara optimal (Ratten \& Tajeddini, 2017). Berbagai penelitian empiris telah dilaksanakan oleh peneliti terdahulu yang membuktikan bahwa risk taking dalam entrepreneurial orientation memiliki dampak yang positif terhadap family firm performance (Basco et al. 2019) (HernandezPerlines 2018) (Winata \& Wijaya 2019) (Mullens, 2018).

Hatak et al., 2016) meneliti efek moderasi dari komitmen keluarga pemilik dalam manajerial terhadap perusahaan pada hubungan antara inovasi dan kinerja perusahaan dan melihat interaksi antara inovasi dan komitmen keluarga sebagai sumber daya yang mempengaruhi kinerja perusahaan. Penelitian terbaru (Aloulou, 2018) berusaha meneliti 
keterlibatan keluarga dalam ruang lingkup keputusan strategis terhadap kinerja perusahaan menemukan dan tidak menemukan hasil. Hipotesis yang dibentuk dalam penelitian adalah: $\mathrm{H}_{1}$ : Innovativeness berpengaruh terhadap family firm performance

$\mathrm{H}_{2}$ : Proactiveness berpengaruh terhadap family firm performance

$\mathrm{H}_{3}$ : Risk taking berpengaruh terhadap family firm performance

$\mathrm{H}_{4}$ : Family involvement memoderasi Innovativeness terhadap family firm performance

$\mathrm{H}_{5}$ : Family involvement memoderasi Proactiveness terhadap family firm performance

$\mathrm{H}_{6}$ : Family involvement memoderasi Risk taking terhadap family firm performance

\section{METODE}

Pendekatan penelitian memakai metode kuantitatif. Populasi yang digunakan penelitian ini ialah seluruh perusahaan keluarga yang diwakilkan oleh pemilik, CEO, atau pihak yang memegang keputusan strategis perusahaan yang merupakan anggota family business community yang dibentuk di Kota Surabaya namun perusahaannya tersebar diseluruh Indonesia dengan dominan di Surabaya. Sampel dalam peneltian ini diambil menggunakan teknik sensus, sehingga seluruh anggota populasi yang berjumlah 83 perusahaan keluarga dan 76 sampel yang terpilih karena 7 kuesioner tidak kembali dan tidak bisa digunakan karena pengisian yang tidak lengkap dan digunakan sebagai sampel. Jenis dan sumber data yang digunakan ialah data primer dikumpulkan melalui $e$-kuesioner yang dibagikan kepada sampel penelitian.

Penelitian ini akan menggunakan tiga dimensi dari entrepreneurial orientation (X) yang terdiri dari innovativeness $\left(\mathrm{X}_{1}\right)$, proactiveness $\left(\mathrm{X}_{2}\right)$ dan risk taking $\left(\mathrm{X}_{3}\right)$ sebagai variabel independen. Pada prinsipnya, entrepreneurial orientation merupakan faktor penting terhadap kesuksesan pengembangan produk baru, menghasilkan performa finansial dan non-finansial yang tinggi, serta meningkatkan kinerja sosial perusahaan (Popov et al., 2019). Variabel terikat dalam penelitian ini ialah family firm performance (Y). Family involvement $(\mathrm{M})$ digunakan sebagai variabel moderasi dengan menggunakan dummy dalam skala tunggal (dari 0 tanpa keterlibatan keluarga hingga 3 dengan keterlibatan keluarga sepenuhnya. 


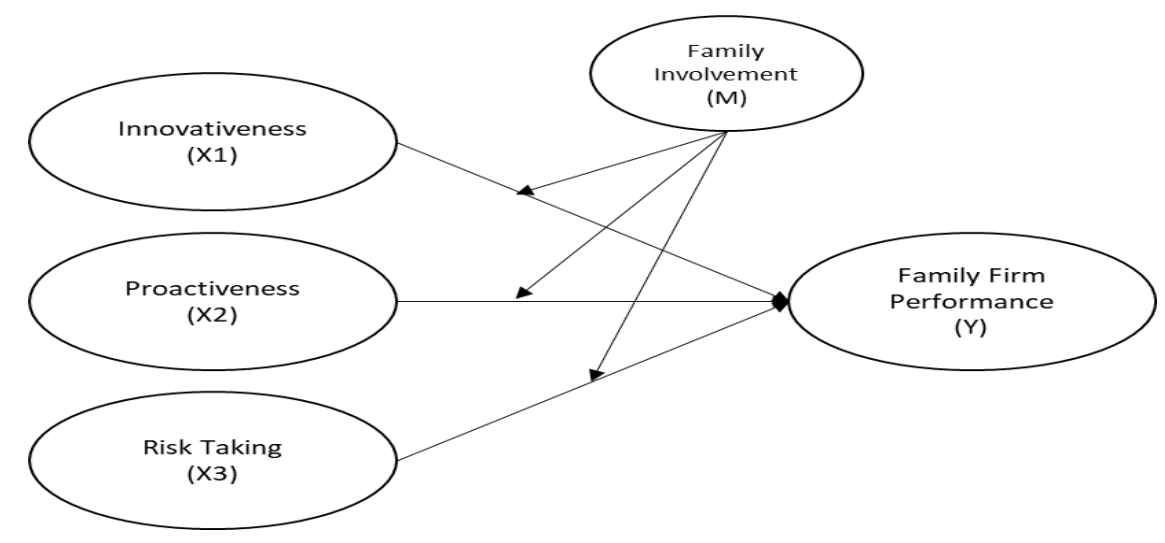

Gambar 1. Model Analisis

Penelitian ini menggunakan alat analisis PLS untuk menganalisis data. Indikator yang digunakan dalam penelitian yang digunakan mengacu (Aloulou, 2018) (Basco et al., 2019) (Kallmuenzer \& Peters, 2017) yang tertera tabel dibawah:

Tabel 1. Indikator Penelitian

\begin{tabular}{|c|c|}
\hline Variabel & Indikator \\
\hline \multirow[t]{3}{*}{ Innovativeness } & Pengembangan produk atau jasa \\
\hline & Memasarkan variasi produk atau jasa yang baru \\
\hline & Melakukan research and development untuk inovasi produk maupun jasa \\
\hline \multirow[t]{7}{*}{ Proactiveness } & Inisiatif atau tindakan strategis baru perusahaan mendahului pesaing dalam produk \\
\hline & Inisiatif atau tindakan strategis baru perusahaan mendahului pesaing dalam jasa \\
\hline & $\begin{array}{l}\text { Inisiatif atau tindakan strategis baru perusahaan mendahului pesaing dalam teknik } \\
\text { administrasi }\end{array}$ \\
\hline & Inisiatif atau tindakan strategis baru perusahaan mendahului pesaing dalam teknik operasi \\
\hline & $\begin{array}{l}\text { Inisiatif atau tindakan strategis baru perusahaan mendahului pesaing dalam teknik } \\
\text { pemasaran }\end{array}$ \\
\hline & Kompetisi bersifat kompetitif atau damai \\
\hline & Pengambilan tindakan reaktif secara langsung terhadap tantangan kompetitor \\
\hline \multirow[t]{3}{*}{ Risk Taking } & Keterlibatan dalam proyek investasi berisiko sedang yang menjanjikan profit \\
\hline & Keterlibatan dalam investasi berskala kecil \\
\hline & Tidak terlibat dalam keputusan berisiko (menghindari keputusan berisiko) \\
\hline \multirow{5}{*}{$\begin{array}{l}\text { Family Firm } \\
\text { Performance }\end{array}$} & Kinerja perusahaan \\
\hline & Profitabilitas \\
\hline & Pertumbuhan jumlah konsumen \\
\hline & Total aset perusahaan \\
\hline & Persaingan kompetitor baru yang dihadapi perusahaan \\
\hline
\end{tabular}

\section{HASIL DAN PEMBAHASAN}

\section{Hasil Penelitian}

Pengujian dilakukan dengan alat PLS dengan menguji outer model serta inner model. Outer model dilakukan evaluasi untuk melihat keandalan dan keabsahan instrumen. Inner model dilakukan untuk menguji signifikansi dan melihat efek moderasi dalam penelitian. 


\section{Evaluasi Model Pengukuran}

Evaluasi pengukuran outer model digunakan dengan melihat nilai AVE dan loading faktor dari setiap indikator. Hasil uji dalam penelitian ini membuang indikator X2.4, X3.3, dan Y6 yang tidak sesuai digunakan dalam penelitian karena menyebabkan nilai AVE $<0,5$. Uji validitas menunjukkan hasil valid karena memiliki nilai AVE >0,5. Uji reliabilitas melihat composite reliability untuk menunjukkan hasil yang reliabel jika memiliki nilai $>0,70$. Hasil outer model dapat dilihat di Gambar 2 yang menunjukkan nilai loading factor dan nilai AVE untuk validitas yang telah memenuhi syarat $>0.5$ dan composite reliability yang dihasilkan untuk reliabilitas diatas 0.7 .

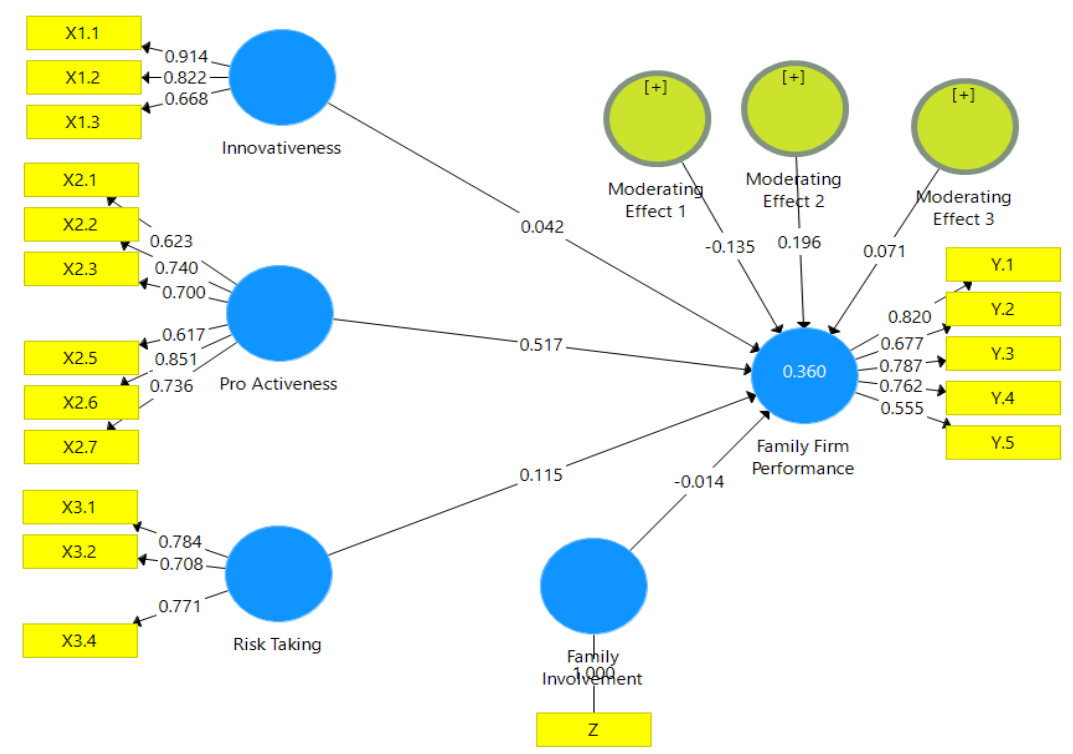

Gambar 2. Outer Model

\section{Evaluasi Inner Model}

Uji inner model variabel eksogen antara variabel eksogen yaitu innovativeness, proactiveness, risk taking terhadap variabel endogen yaitu family firm performance serta uji moderasi dilakukan dengan variable moderasi yaitu family involvement. Hasil uji inner model dinyatakan signifikan ketika pvalue lebih kecil 0.05 dan t statistik lebih besar 1.96

Tabel 2. Hasil Uji Signifikansi dan Uji Moderasi

\begin{tabular}{lccc}
\hline \multicolumn{1}{c}{ Hubungan } & t Statistik & p value & Kesimpulan \\
\hline Innovativeness - Family Firm Performance & 0.361 & 0.716 & Tidak Signifikan \\
Proactiveness - Family Firm Performance & 5.199 & 0.000 & Signifikan \\
Risk Taking - Family Firm Performance & 0.850 & 0.395 & Tidak Signifikan \\
Moderating Effect 1 - Family Firm Performance & 1.176 & 0.239 & Tidak Signifikan \\
Moderating Effect 2 - Family Firm Performance & 1.684 & 0.395 & Tidak Signifikan \\
Moderating Effect 3 - Family Firm Performance & 0.501 & 0.616 & Tidak Signifikan \\
\hline
\end{tabular}


Hasil uji inner model yang sesuai di tabel diatas menunjukkan hanya proactiveness yang berpengaruh signifikan terhadap family firm performance dengan hasil $p$ value yang lebih kecil dari 0,05. Pengaruh variable lain yaitu innovativeness dan risk taking tidak berpengaruh signifikan. Hasil uji moderasi juga menunjukkan tidak adanya pengaruh signifikan. Dari hasil uji moderasi menunjukan family involvement sebagai potensial moderasi terhadap hubungan innovativeness dan risk taking terhadap family firm performance. Sedangkan dalam hubungan dengan proactiveness terhadap family firm performance, family involvement menjadi predictor moderasi.

\section{Pembahasan Penelitian}

\section{Pengaruh Innovativeness terhadap Family Firm Performance}

Inovasi adalah penerapan dan implementasi produk, proses, prosedur, dan gagasan baru secara sadar oleh unit atau organisasi, yang bertujuan untuk memberi manfaat bagi individu, kelompok, organisasi, dan seluruh komunitas (Radziwon \& Bogers, 2019). Pengujian hipotesis pertama dalam penelitian ini menunjukkan hasil variabel innovativeness tidak berpengaruh terhadap performa perusahaan keluarga. Hasil penelitian ini sesuai dengan hasil studi empiris terdahulu yang menyatakan bahwa dalam beberapa kasus, innovativeness juga dapat memberikan efek yang non signifikan pada performa perusahaan keluarga (Aloulou, 2018) (Chong et al., 2019) (Hernández-Linares et al., 2019) (Winata \& Wijaya, 2019).

Berdasarkan hasil kuesioner yang dibagikan, indikator yang memiliki rata-rata terendah ialah pernyataan "Perusahaan saya melaksanakan Research \& Development (R\&D) untuk inovasi produk maupun jasa". Sikap ini menunjukkan bahwa perusahaan keluarga yang tergabung dalam komunitas memiliki kecenderungan research \& developmenet yang rendah. Hal tersebut mempengaruhi perilaku mereka dalam pengambilan tindakan inovatif pula. Pada hasil kuesioner, bidang perusahaan yang mendominasi hasil kuesioner merupakan perusahaan bidang retail dengan jumlah 23 perusahaan. Berdasarkan penelitian (Hristov \& Reynolds, 2015), seringkali perusahaan retailer memiliki tingkat intensitas $R \& D$ yang lebih rendah dibandingkan dengan perusahaan bidang lainnya. Hal tersebut disebabkan karena perusahaan retail memiliki ruang lingkup untuk inovasi yang kecil dan tidak luas pada produk.

Hal lain yang mempengaruhi hasil penelitian ini dapat dilihat melalui hasil kuesioner mengenai peristiwa yang dialami perusahaan, menunjukkan bahwa sebanyak 46 perusahaan merasa bahwa kondisi perusahaan berjalan seperti normal biasanya. Berjalan seperti normal 
biasanya menandakan bahwa tidak terdapat perkembangan yang pesat yang dialami perusahaan selama berdiri, dimana rata-rata perusahaan berdiri selama 0-20 tahun. Kondisi yang dialami oleh suatu perusahaan, dapat mempengaruhi tindakan atau perilaku yang diterapkan pada perusahaannya. Seringkali, perusahaan yang melakukan inovasi merupakan perusahaan yang sedang mengalami keadaan krisis (Ratten, 2020).Sehingga dapat dikatakan bahwa beberapa perusahaan tidak melaksanakan kegiatan inovatif saat tidak mengalami masa kritis. Inovasi mungkin didukung dengan orientasi jangka panjang terhadap budaya, sementara pentingnya proaktif mungkin ditopang oleh penghindaran ketidakpastian tingkat rendah (Basco et al. 2019)

\section{Pengaruh Proactiveness terhadap Family Firm Performance}

Proaktif adalah proses inisiatif dalam menyelesaikan sesuatu, yang dapat digunakan untuk mengantisipasi tugas di masa depan. Sikap ini menjadi tolak ukur untuk mempersiapkan perusahaan menghadapi tantangan masa depan agar perusahaan dapat fokus pada positioning perusahaan untuk memanfaatkan peluang tersebut (Chong et al., 2019). Hasil pengujian hipotesis kedua, diketahui bahwa variabel proactiveness memiliki pengaruh terhadap performa perusahaan keluarga. Berbagai studi empiris terdahulu juga memiliki hasil yang sama dengan penelitian ini (Aloulou 2018) (Basco et al. 2019) (Chong et al. 2019) (Hernández-Linares et al. 2019) (Hernandez-Perlines 2018) (Winata and Wijaya 2019).

Hal tersebut sejalan dengan penelitian (Kallmuenzer \& Peters 2017) bahwa tindakan proaktif dapat diketahui melalui perkembangan kompetitif yang dilakukan oleh suatu perusahaan dibandingkan dengan perusahaan saingannya. Penelitian oleh (Linton \& Kask, 2017) juga mendukung hasil penelitian ini dengan pernyataan bahwa sikap proaktif perusahaan akan mempengaruhi kinerja perusahaan tersebut menjadi lebih tinggi dibandingkan kompetitornya. Tindakan proaktif yang dilakukan oleh pemilik perusahaan adalah dimana mereka berusaha untuk lebih baik dibandingkan dengan kompetitor dalam hal melakukan inovasi dan peningkatan dalam area produk baru, jasa layanan, pemasaran, merespon kebutuhan konsumen. Melalui hasil kuesioner yang menyatakan persitiwa yang dialami perusahaan responden, terdapat 25 perusahaan yang melakukan ekspansi atau membuka cabang baru selama perusahaan berdiri hingga saat ini. Kegiatan tersebut juga dapat menambah bukti bahwa perusahaan keluarga dalam komunitas melaksanakan kegiatan proaktif berupa ekspansi atau membuka cabang baru. Hal ini menjadi indikasi kuat bahwa seorang pengusaha harus memiliki sikap inisiatif untuk aktif merespon segala aktivitas dan kebutuhan pasar. Sikap proaktif yang 
dibangun akan membuat seorang pengusaha mampu untuk menangkap dan memanfaatkan peluang yang ada.

\section{Pengaruh Risk Taking terhadap Family Firm Performance}

Risk taking adalah proses bisnis perusahaan dalam mengambil risiko bisnis pada permulaan proyek bisnis baru yang mempengaruhi peluang bisnis perusahaan dalam kemampuan dan hasil dimasa depan (Chong et al., 2019). Hasil pengujian hipotesis ketiga dalam penelitian ini menunjukkan hasil yang menyatakan bahwa variabel proativeness memiliki tidak pengaruh terhadap performa perusahaan keluarga. Hasil penelitian ini berbeda dengan hasil studi empiris terdahulu yang menyatakan bahwa dimensi risk taking pada entrepreneurial orientation berdampak secara positif dan signifikan pada family firm performance (Basco et al. 2019) (Hernandez-Perlines 2018) (Winata \& Wijaya, 2019). Namun, didukung oleh hasil penelitian dari (Aloulou, 2018) yang menemukan hasil tidak signifikan untuk perusahaan keluarga di Arab.

Pada kuesioner yang dibagikan, didapat hasil bahwa mayoritas responden memiliki kecenderungan untuk meningkatkan komitmen sumber daya perusahaan secara bertahap dan ketika mengambil sebuah keputusan, perusahaan cenderung menunggu dan melihat situasi secara berhati-hati. Hal tersebut disebabkan karena berdasarkan hasil kuesioner mengenai persitiwa yang dialami perusahaan, terdapat 35 perusahaan yang mengalami kesulitan keuangan atau bangkrut saat beroperasi, dan tidak semua dapat bangkit kembali. Namun mayoritas perusahaan dalam sampel penelitian ini tetap berjalan normal seperti biasa walaupun ada beberapa kesulitan keuangan dan tetap berupaya melakukan ekspansi. Sehingga dalam pengambilan keputusan, perusahaan-perusahaan yang sudah pernah merasakan kondisi kesulitan keuangan akan cenderung lebih berhati-hati dalam langkah kedepannya. Tindakan risk taking memerlukan implementasi perhitungan risiko agar dapat memahami apa saja manfaat yang dipertaruhkan perusahaan (Ratten \& Tajeddini, 2017). Dengan adanya pertimbangan, akan membuat perusahaan tersebut mengambil tindakan berisiko yang berdampak secara optimal pada perusahannya. Meskipun pengambilan tindakan berisiko dilaksanakan secara berhati-hati, perusahaan tetap tidak bisa menghindarinya dalam kegiatan berbisnis. Hal tersebut disebabkan karena peluang selalu diikuti dengan adanya persaingan ketat dari pesaing lainnya. 
Persaingan kompetitor yang dihadapi perusahaan responden makin meningkat tiap tahunnya. Keadaan ini tidak menghentikan perusahaan keluarga dalam komunitas untuk tetap melakukan ekspansi serta rebranding, meskipun beberapa pernah mengalami kesulitan keuangan. Hal tersebut membuktikan bahwa dalam pengambilan keputusan, perusahaan tetap mempertimbangkan pengambilan keputusan yang menghasilkan keuntungan meskipun terdapat risiko dalam tindakannya. Oleh sebab itu, mayoritas perusahaan keluarga akan cenderung untuk tidak mengejar risiko yang tinggi, namun perusahaan akan cenderung meminimalisir risiko dan meraih peluang terbaik dalam ketidakpastian (Cho \& Lee, 2018).

Hasil temuan ini di Indonesia mirip dengan temuan (Basco et al. 2019) yang dilakukan di Cina dimana dimensi risk taking kurang relevan dibandingkan kedua dimensi lain yaitu proactiveness dan innovativeness dalam konfigurasi khusus negara yang berorientasi kewirausahaan. Dimensi risk taking dapat dihubungkan antara keterikatan ekonomi pemilik bisnis dan rasa cinta emosional dengan bisnis. Situasi ini memposisikan baik pemilik maupun manajer dalam berhati-hati terhadap jenis kerugian yang ditimbulkan perilaku berisiko mereka. Hal menarik dalam temuan ini dimana tidak adanya pengaruh risk taking dalam kinerja perusahaan mereka bukan berarti bahwa pemilik bisnis tidak memperhatikan risk taking dalam keputusannya namun fundamental ekonomi yang dirasa kuat dalam mengoperasionalkan perusahaan telah mampu dibangun. Mayoritas perusahaan keluarga yang diamati setidaknya telah mampu melewati gejolak ekonomi di Indonesia mulai masa periode krisis ekonomi 1998 kemudian krisis ekonomi global 2008 tidak menghambat operasional perusahaan dan masih terus eksis. Akan tetapi kondisi resesi ekonomi yang disebabkan pandemi covid 19 masih perlu dilihat dampaknya terhadap kinerja perusahaan dan pandangan dari pemilik bisnis terhadap tindakan risk taking yang dilakukan untuk mempertahankan kinerja perusahaan perlu diuji dimasa depan.

\section{Hubungan Moderasi Family Involvement}

Hasil yang menunjukkan tidak adanya moderasi dari family involvement menunjukkan bisnis keluarga dengan keterlibatan anggota keluarga yang lebih tinggi cenderung lebih konservatif dan enggan mengambil risiko dalam membuat keputusan strategi (Naldi et al., 2007) (Aloulou, 2018). Keterlibatan keluarga yang tinggi bisa berarti diartikan bahwa walaupun terlibat secara operasional namun anggota keluarga tidak memiliki kekuasaan untuk membuat kebijakan dan arah perusahaan. Anggota keluarga cenderung mengadopsi praktik manajemen yang cermat dan strategi yang tidak berisiko untuk menjamin kelangsungan perusahaan mereka 
dan menjaga stabitlitas keuangan dan kekayaan non finansial (Naldi et al., 2007). Hal ini setidaknya didukung dengan perusahaan keluarga yang diamati dalam penelitian ini masih didominasi dengan generasi pertama sebesar $80 \%$ sedangkan sisanya sudah mulai melibatkan generasi kedua untuk mengelola perusahaan. Dalam konteks tata kelola organisasi yang melibatkan anggota keluarga dalam penelitian ini dapat dilihat bahwa peranan anggota keluarga lain belum hingga pada tataran pembuat keputusan. Disisi lain yang perlu diketahui yang berbeda dengan penelitian terdahulu yang eksis adalah obyek penelitian yang digunakan dalam penelitian ini adalah mayoritas perusahaan keluarga yang skalanya masih menengah dengan nilai aset makasimal Rp 10 milyar dan nilai omset Rp 2,5 - Rp 50 milyar dalam 1 tahun. Pada perusahaan yang masih skala menengah untuk struktur organisasi dan tata kelola perusahaan masih sederhana dibandingkan dengan perusahaan yang besar sehingga keterlibatan keluarga masih bersifat adminstratif.

Temuan ini mendukung argumen bahwa elemen manajemen dan tata kelola perlu diperhitungkan untuk memahami hubungan antara pengambilan risiko dan dimensi lain dari entrepreneurship di perusahaan keluarga yang sudah mapan (Aloulou, 2018). Hasil yang tidak menunjukkan keterlibatan anggota keluarga dalam tata kelola organisasi terhadap kinerja perusahaan tidak boleh dianggap sebagai penghambat pengembangan sumber daya dan kemampuan yang diperlukan untuk proses berwirausaha dalam kegiatan operasi mereka. Sebaliknya, perusahaan keluarga harus mempersiapkan dan mengintegrasikannya anggota kelaurga untuk sukses memimpin perusahaan dengan memanfaatkan kompetensi, keterampilan, dan koneksi untuk memacu aktivitas kewirausahaan dan melibatkan mereka terhadap aktivitas yang mendukung kinerja perusahaan. Temuan ini setidaknya akan harus diuji lagi di masa depan apakah berbagai jenis keterlibatan keluarga seperti dalam bentuk kepemilikan bersama dapat menentukan kinerja perusahaan karena keluarga yang terlibat memiliki kekuasaaan dalam menentukan arah dan kebijakan perusahaan.

\section{KESIMPULAN}

Hasil penelitian pada dimensi inovasi, penerapan tindakan inovatif akan bervariatif sesuai dengan bidang dan kondisi yang dihadapi perusahaan tersebut. Menerapkan dimensi proaktif dalam kegiatan perusahaan akan mendorong performa perusahaan keluarga menjadi lebih unggul dibandingkan dengan kompetitornya, sedangkan pada dimensi risk taking, kondisi atau peristiwa yang pernah dialami oleh perusahaan tersebut akan mempengaruhi pengambilan 
keputusan berisikonya. Olehnya, diharapkan perusahaan keluarga dapat mempertimbangkan profitabilitas yang akan didapatkan melalui tindakan inovatif, proaktif dan meminimalisir risiko dalam meraih peluang terbaik tersebut. Berdasarkan penelitian yang telah dilaksanakan, penelitian ini dapat membagikan wawasan dan masukan kepada para pemegang keputusan dalam perusahaan keluarga untuk menerapkan nilai-nilai dimensi entrepreneurial orientation sesuai dengan kondisi dan persaingan yang dihadapi perusahaan. Harapannya, perusahaan keluarga dapat mengambil keputusan dalam kegiatan berbisnis dengan tepat untuk meningkatkan performa perusahaannya. Penelitian ini menunjukkan bahwa terdapat perbedaan penerapan dimensi entrepreneurial orientation tergantung pada kondisi dan bidang perusahaan keluarga yang dijalankan.

Penelitian ini memiliki keterbatasan dimana kuesioner yang disebar tidak semuanya kembali dan dijawab utuh. Hal tersebut dapat mempengaruhi hasil pengujian pada penelitian ini. Saran bagi pelaku bisnis keluarga, diperlukan pertimbangan profitabilitas dan risiko yang dihadapi perusahaan saat pengambilan keputusan. Keputusan yang optimal dapat dicapai dengan memperhatikan kondisi pasar dan mengambil peluang secara proaktif dan inovatif, namun harus tetap meminimalisir risiko dalam meraih peluang tersebut. Bagi peneliti berikutnya, perlu mempertimbangkan dimensi lain dari entrepreneurial orientation yang juga dapat memberikan pengaruh terhadap family firm performance seperti dimensi competitive aggressiveness dan dimensi autonomy. Penelitian selanjutnya disarankan menggunakan ruang lingkup yang lebih luas, sehingga data yang didapatkan menjadi lebih bervariatif.

\section{DAFTAR PUSTAKA}

Abdilahi, M. H., Hassan, A. A., \& Muhumed, M. M. (2017). The Impact of Innovation on Small and Medium Enterprises Performance: Empirical Evidence from Hargeisa, Somaliland. International Journal of Academic Research in Business and Social Sciences. https://doi.org/10.6007/ijarbss/v7-i8/3202.

Aloulou, W. J. (2018). Examining entrepreneurial orientation's dimensions - performance relationship in Saudi family businesses: Contingency role of family involvement in management. Journal of Family Business Management, 8(2), 126-145. https://doi.org/10.1108/JFBM-02-2018-0007.

Basco, R., Hernández-Perlines, F., \& Rodríguez-García, M. (2019). The effect of entrepreneurial orientation on firm performance: A multigroup analysis comparing China, Mexico, and Spain. Journal of Business Research. https://doi.org/10.1016/j.jbusres.2019.09.020.

Cho, Y. H., \& Lee, J.-H. (2018). Entrepreneurial orientation, entrepreneurial education and performance. Asia Pacific Journal of Innovation and Entrepreneurship. 
https://doi.org/10.1108/apjie-05-2018-0028.

Chong, A. L., Loong Lee, W., \& Ramayah, T. (2019). The effects of entrepreneurial orientation on the performance of the Malaysian manufacturing sector. Asia-Pacific Journal of Business Administration. https://doi.org/10.1108/APJBA-06-2018-0099.

Family Firm Institute Inc. (2017). Global Data Points. Family Firm Institute.

Hasan, G. (2019). Motivasi, Kepuasan, Karakteristik, Kepemimpinan dan Keadilan Terhadap Komitmen Organisasi. Efisiensi : Kajian Ilmu Administrasi, 16(1), 21-32. https://doi.org/10.21831/efisiensi.v16i1.24474.

Hatak, I., Kautonen, T., Fink, M., \& Kansikas, J. (2016). Innovativeness and family-firm performance: The moderating effect of family commitment. Technological Forecasting and Social Change, 102, 120-131. https://doi.org/10.1016/j.techfore.2015.02.020.

Hernández-Linares, R., Kellermanns, F. W., López-Fernández, M. C., \& Sarkar, S. (2019). The effect of socioemotional wealth on the relationship between entrepreneurial orientation and family business performance. BRQ Business Research Quarterly. https://doi.org/10.1016/j.brq.2019.03.002.

Hernandez-Perlines, F. (2018). Moderating effect of absorptive capacity on the entrepreneurial orientation of international performance of family businesses. Journal of Family Business Management, 8(1), 58-74. https://doi.org/10.1108/JFBM-10-2017-0035.

Hristov, L., \& Reynolds, J. (2015). Perceptions and practices of innovation in retailing. International Journal of Retail \& Distribution Management. https://doi.org/10.1108/ijrdm-09-2012-0079.

Kallmuenzer, A., \& Peters, M. (2017). Exploring entrepreneurial orientation in family firms: the relevance of social embeddedness in competition. International Journal of Entrepreneurship and Small Business. https://doi.org/10.1504/ijesb.2017.10002036.

Kuswantoro, A. (2015). Efisiensi: Kajian Ilmu Administrasi. Jurnal Efisiensi, XIII(1), 76. https://journal.uny.ac.id/index.php/efisiensi/article/view/11679/8397.

Linton, G., \& Kask, J. (2017). Configurations of entrepreneurial orientation and competitive strategy for high performance. Journal of Business Research. https://doi.org/10.1016/j.jbusres.2016.08.022.

Mullens, D. (2018). Entrepreneurial orientation and sustainability initiatives in family firms. Journal of Global Responsibility. https://doi.org/10.1108/jgr-03-2017-0020.

Naldi, L., Nordqvist, M., Sjöberg, K., \& Wiklund, J. (2007). Entrepreneurial orientation, risk taking, and performance in family firms. Family Business Review. https://doi.org/10.1111/j.1741-6248.2007.00082.x.

Olaore, R. A., \& Oyeleke, G. O. (2019). The Significance of Innovation to the Performance of Family Business in Nigeria. Global Scientific Journals, 7(2), 168-1774. https://doi.org/10.2139/ssrn.2852008.

Popov, B., Varga, S., Jelić, D., \& Dinić, B. (2019). Psychometric evaluation of the Serbian adaptation of the individual entrepreneurial orientation scale. Education and Training. https://doi.org/10.1108/ET-03-2018-0058. 
PricewaterhouseCoopers. (2018). Family business survey 2018: Indonesia report. Www.Pwc.Com, 1-44.

Puni A. Anjungsari. (2016, November). IFC and Indonesia's Family Business Nusantara Foundation Help Family-Owned Enterprises Improve Cooporate Governance. International Finance Corporation.

Radziwon, A., \& Bogers, M. (2019). Open innovation in SMEs: Exploring inter-organizational relationships in an ecosystem. Technological Forecasting and Social Change, 146, 573587. https://doi.org/10.1016/j.techfore.2018.04.021.

Ratten, V. (2020). Coronavirus (Covid-19) and entrepreneurship: cultural, lifestyle and societal changes. Journal of Entrepreneurship in Emerging Economies. https://doi.org/10.1108/JEEE-06-2020-0163.

Ratten, V., \& Tajeddini, K. (2017). Innovativeness in family firms: an internationalization approach. Review of International Business and Strategy, 27(2), 217-230. https://doi.org/10.1108/RIBS-12-2016-0085.

Rezaei, J., \& Ortt, R. (2018). Entrepreneurial orientation and firm performance: the mediating role of functional performances. Management Research Review. https://doi.org/10.1108/MRR-03-2017-0092.

Sumawidjaja, R. N., Suryana, Ahman, E., \& Machmud, A. (2019). The impact of entrepreneurial competencies on creative industry performance in Indonesia. Journal of Entrepreneurship Education.

Taouab, O., \& Issor, Z. (2019). Firm Performance: Definition and Measurement Models. European Scientific Journal ESJ. https://doi.org/10.19044/esj.2019.v15n1p93.

Wijaya, A., \& Wijaya, B. (2017). Analisis suksesi pada bisnis keluarga berbasis family owned enterprise (FOE). Conference on Management and Behavioral Studies, 186-193.

Winata, W., \& Wijaya, A. (2019). Pengaruh Hubungan Dimensi Orientasi Kewirausahaan Terhadap Kinerja Bisnis Keluarga Di Jakarta Barat. Jurnal Manajerial Dan Kewirausahaan, I(4), 707-716.

\section{UCAPAN TERIMA KASIH}

Ucapan terima kasih kepada para seluruh pihak dalam family business community Angkatan VIII Surabaya yang menjadi responden dalam penelitian ini.

\section{PROFIL PENULIS}

Krismi Budi Sienatra (Sinta ID : 6007421) selaku penulis adalah pengajar di Universitas Ciputra Surabaya yang merupakan lulusan Universitas Brawijaya. Syellen Laudo adalah mahasiswa program sarjana Universitas Ciputra Surabaya. 